\title{
$\mathrm{Fe}-0.7 \mathrm{wt} . \% \mathrm{C}-2.3 \mathrm{wt} . \% \mathrm{Si}-0.3 \mathrm{wt} . \% \mathrm{Mn}$ 강의 오스템퍼링 변태 거동 신상윤·이도훈·김서은 · 예병준 ${ }^{\dagger}$ \\ 경북대학교
}

\section{The Austempering Transformation Behavior of Fe-0.7wt.\%C-2.3wt.\%Si-0.3wt.\%Mn Steel}

\author{
Sang-Yun Shin, Do-Hoon Lee, Seo-Eun Kim and Byung-Joon Ye ${ }^{\dagger}$ \\ Depatment of Metallurgical Engineering Graduate School of Kyungpook National University, Daegu 702-701, Korea
}

\begin{abstract}
The austempering transformation behavior in Fe-0.7wt.\%C-2.3wt.\%Si-0.3wt.\%Mn steel is investigated. Each specimen was austenitized for $60 \mathrm{~min}$ at $900^{\circ} \mathrm{C}$, and austempered at $380^{\circ} \mathrm{C}$ for different time periods varying from 2 min to 256 min. After the austempering heat treatment, the Stage I and II evolutions are performed using optical metallography, X-ray diffraction and image analyses. Variations in the X-ray diffraction patterns and lattice parameters of the ferrite and austenite demonstrate that the residual austenite decomposes into ferrite and carbide during the Stage II evolution; moreover the amount of ferrite increases during the Stage I evolution. While the amount of austenite increases during Stage I, it dicreases during Stage II. Overall, the variations in the volume fractions of the microstructure and carbide formation in stages I and II meet high temperature austempering reaction of the ausferrite microstructure.
\end{abstract}

Key words : Casting, Hot rolling, Processing Window, Austempering, Austempered Ductile Cast Iron, Heat Treatment, Ausferrite

\section{1. 서 론}

\section{오스템퍼드 구상흑연주철(ADI)이란 구상흑연주철을 오스템퍼} 링 처리하여 기지조직인 펄라이트와 페라이트를 우수한 특성을 지닌 페라이트와 고탄소 오스테나이트(일명 오스페라이트) 조직 으로 변태시킨 것을 말한다. 오스페라이트 조직을 갖는 $\mathrm{ADI}$ 는 인장강도가 구상흑연주철의 두 배 이상이며 $(850 \sim 1600 \mathrm{MPa})$, 주철에서 얻을 수 없는 높은 연신율( $13 \%)$ 을 가지는 우수한 재질이다[1-3]. 그러나 $\mathrm{ADI}$ 의 조직적 특성으로 인해 고강도와 내마모성이 요구되는 분야에 그 적용이 국한되었다. 또한 $\mathrm{ADI}$ 의 기지에 포함되어 있는 흑연 노듈이 하중을 받는 환경에서 크랙의 시발점으로 작용해 충격강도와 파괴인성을 감소시키고, 높은 마모조건의 환경에서 제품의 수명을 단축시킴으로써 일종 의 결함으로 작용한다[4].

이를 보완하기 위해 몇 몇 연구자들은 기존의 $\mathrm{ADI}$ 에 만족
하지 않고 보다 더 우수한 소재를 얻고자 오스템퍼드 고탄소. 고규소강 강을 연구하게 되었다[5-7]. 특히, 규소를 $2.3 \mathrm{wt} . \%$ 로 고정시키고 오스템퍼드 구상흑연주철의 기지조직이 함유하고 있 는 탄소량과 비슷하게 $0.7 \mathrm{wt} \%$ 로 맞추어 흑연노듈이 없는 순 수한 오스페라이트 조직을 형성시킴으로써 양호한 오스페라이트 조직과 기계적 성질(인장강도: $1,300 ~ 2,200 \mathrm{MPa}$, 연신율: 10 $25 \%$ )을 가지는 오스템퍼드 고탄소·고규소강(austempered high carbon and high silicon, 일명 ACSS)을 개발할 수 있었다 [8]. 그러나 높은 관심과 달리 오스템퍼드 고탄소·고규소강의 주 조직인 오스페라이트 조직에 대한 규명은 부족한 실정이다. 따라서 본 연구에서는 화학조성이 $\mathrm{Fe}-0.7 \mathrm{wt} . \% \mathrm{C}-2.3 \mathrm{wt} . \% \mathrm{Si}-$ $0.3 \mathrm{wt} . \% \mathrm{Mn}$ 인 $\mathrm{ACSS}$ 를 $380^{\circ} \mathrm{C}$ 에서 오스템퍼링 시간(2 256분) 에 따라 오스템퍼링을 한 후, 물 퀜칭을 하였을 때, 각기 다 른 오스템퍼링 시간에 따른 미세조직 분율 변화를 살펴봄으로 써, $\mathrm{ACSS}$ 의 기지조직인 오스페라이트에 대한 오스템퍼링 열처

\footnotetext{
Received: Nov. 22, 2013 ; Revised: Dec. 17, 2013 ; Accepted: Jan. 28, 2014 Journal of Korea Foundry Society Corresponding author: Byung-Joon Ye (Kyungpook National Univ.) 2014. Vol. 34 No. 1, pp. 001 005 Tel: +82-53-950-5567, Fax: +82-53-950-7504 E-mail: bjye@knu.ac.kr http://dx.doi.org/10.7777/jkfs.2014.34.1.001 ISSN 1598-706X / eISSN 2288-8381
}

(C) Korea Foundry Society, All rights reserved.

This is an Open-Access article distributed under the terms of the Creative Commons Attribution Non-Commercial License (http://creativecommons.org/licenses/by-nc/3.0) which permits unrestricted non-commercial use, distribution, and reproduction in any medium, provided the original work is properly cited. 
리 동안의 변태 거동을 보았다.

\section{2. 실험 방법}

\section{1 용해, 주조}

본 실험에 사용한 고탄소·고규소강의 용해는 대기 중에서 $50 \mathrm{~kg}$ 용량의 고주파 유도로에서 실시하였다. 사용한 시편의 장 입원료로는 $4.31 w t . \% \mathrm{C}, 1.61 \mathrm{wt} . \% \mathrm{Si}$ 및 $0.36 \mathrm{wt} . \% \mathrm{Mn}$ 인 선철 (pig iron)과 $0.1 \mathrm{wt} . \% \mathrm{C}$ 및 $0.053 \mathrm{wt} . \% \mathrm{Si}$ 강고철(steel scrap)을 사용하였다. 특히 규소는 고탄소·고규소강에서 가장 좋은 물성 을 나타내는 $2.3 \mathrm{wt} . \%$ 로 고정시켰으며, 또한 가탄제를 첨가하여 $\mathrm{ADI}$ 의 기지조직의 탄소 함유량과 비슷하게 $0.7 \mathrm{wt} \%$ 로 조절하 였다.

그리고 용탕의 온도를 $1640^{\circ} \mathrm{C}$ 로 상승시켜 미리 예열한 레이 들(ladle)에 넣고, 사형의 $\mathrm{CO}_{2}$ 주형에 주입하여 시편을 제조하였 으며, 실험에 사용한 시편의 분석은 발광 분광분석기(emission spectrometer, GVM-1014S)로 분석하였다. 그 분석결과는 Table 1 과 같다.

\section{2 열처리}

오스템퍼링은 염욕에서 Table 2와 같이 각각 온도와 시간을 변화시켜 가면서 진행하였으며, 오스템퍼링 이후에는 탄소의 확 산을 막기 위하여 물 퀜칭을 실시하였다.

\section{3 미세조직 분석}

미세조직 분석을 위해 시편을 폴리싱한 후, $3 \% \mathrm{Nital}$ 로 부 식하여 광학현미경으로 관찰하였으며, 이미지 분석(image analysis)을 통하여 페라이트의 분율을 측정하였다. 또한 잔류 오스테나이트(retained austenite)의 분율은 X-선 회절(Philips Analytical X- Ray)장비를 이용하여 측정하였다.

Table 1. Chemical composition of experimental specimen.

\begin{tabular}{cccccc}
\hline \multirow{2}{*}{ Steels } & \multicolumn{5}{c}{ Composition (wt.\%) } \\
\cline { 2 - 6 } & $\mathrm{C}$ & $\mathrm{Si}$ & $\mathrm{Mn}$ & $\mathrm{P}$ & $\mathrm{S}$ \\
\hline nominal & 0.70 & 2.30 & 0.30 & - & - \\
specimem & 0.71 & 2.26 & 0.42 & 0.014 & 0.014 \\
\hline
\end{tabular}

Table 2. Heat treatment condition.

\begin{tabular}{|c|c|c|c|}
\hline \multicolumn{2}{|c|}{ Austenitizing } & \multicolumn{2}{|c|}{ Austempering } \\
\hline Temp. $\left({ }^{\circ} \mathrm{C}\right)$ & Time(min) & Temp. $\left({ }^{\circ} \mathrm{C}\right)$ & Time(min) \\
\hline 900 & 60 & 380 & $\begin{array}{c}2 \\
4 \\
8 \\
16 \\
32 \\
64 \\
128 \\
256\end{array}$ \\
\hline
\end{tabular}

\section{3. 결과 및 고찰}

\section{1 미세조직}

Fig. 1은 고탄소-고실리콘 강을 $380^{\circ} \mathrm{C}$ 의 온도에서 오스템퍼 링 시간(2 256분)에 따라 오스템퍼링한 후, 물로 퀜칭한 미세 조직을 나타낸다. 에칭에 의해 식각 되어진 부분은 페라이트를 나타내고 있으며, 식각 되지 않은 부분은 오스테나이트와 마르 텐사이트이다. Fig. 1을 통해서 오스템퍼링 시간이 증가함에 따라 페라이트의 생성이 점차 증가함을 관찰할 수 있다. 특히, 32분의 Fig. 1(e)는 완전한 오스페라이트조직을 보이며, 256분 의 (h)로 갈수록 탄화물이 생성되어 페라이트와 잔류오스테나이 트의 경계가 흐려지는 것을 확인할 수 있다.

\section{2 탄화물의 생성}

Fig. 2는 각 열처리 조건에 대한 X-선 회절 패턴을 나타낸 것이다. 여기에서 128 과 256 분은 32 와 64 분에서와 달리 $42^{\circ}$ 부근에서 미세한 피크가 나타남을 관찰할 수 있다. 이것은 2 단

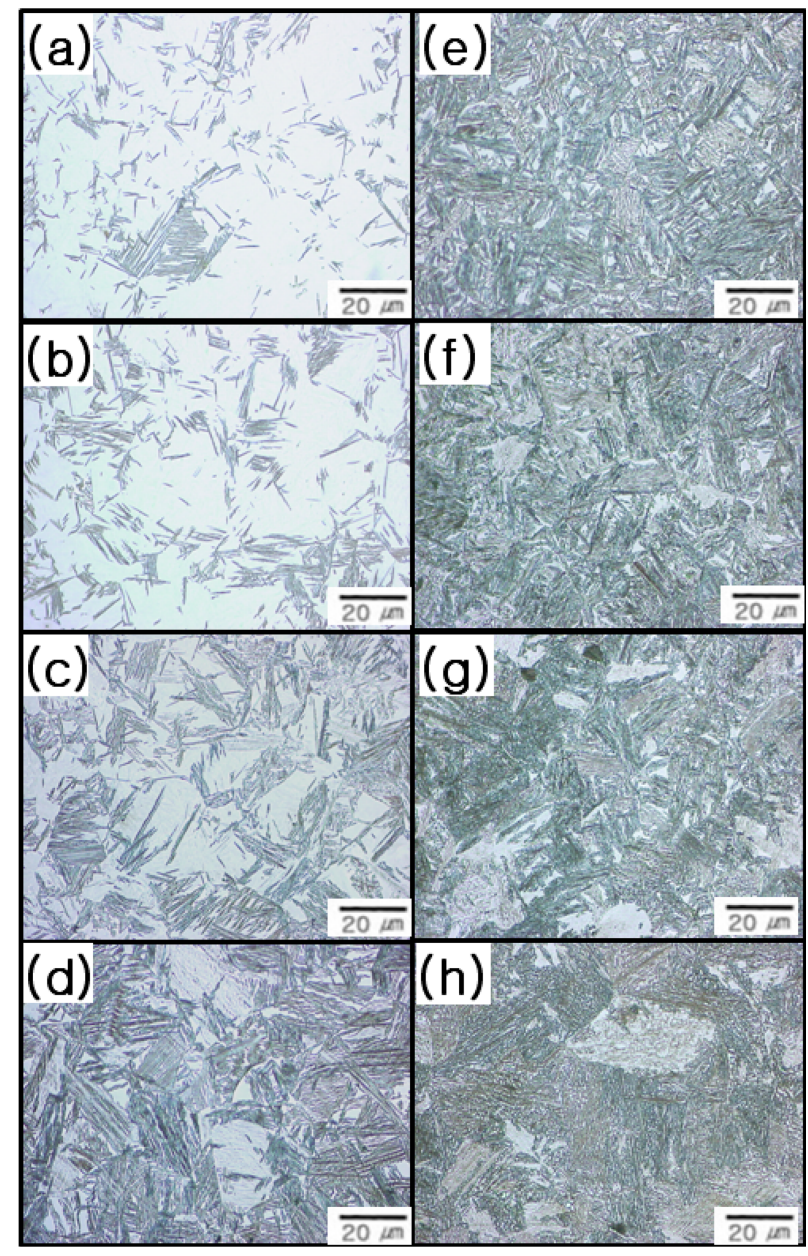

Fig. 1. Microstructures of specimen austempered at $380^{\circ} \mathrm{C}$ with austempering times; (a) 2, (b) 4, (c) 8, (d) 16, (e) 32, (f) 64, (g) 128 and (h) $256 \mathrm{~min}$. 

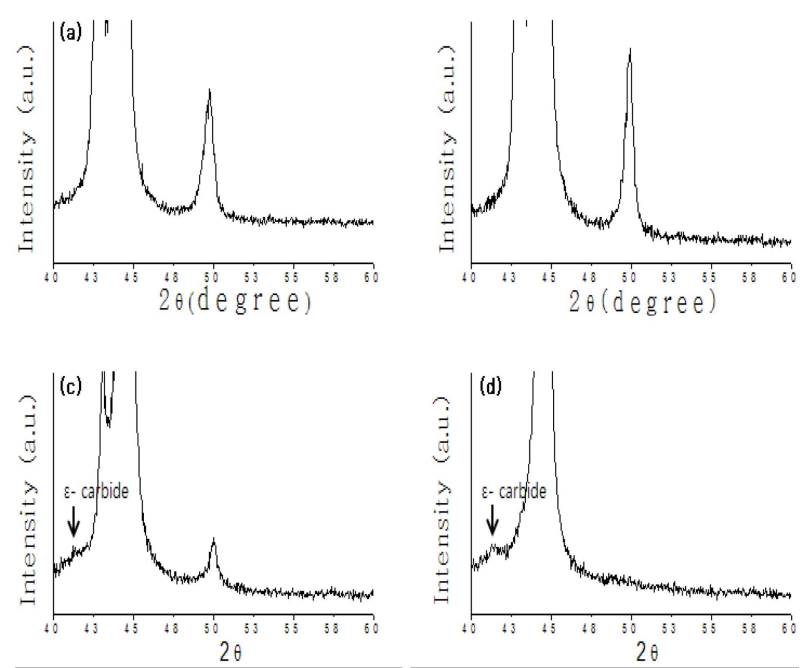

Fig. 2. X-ray diffraction peaks of carbide at $380^{\circ} \mathrm{C}$ with austempering times; (a) 32, (b) 64, (c) 128 and (d) $256 \mathrm{~min}$.

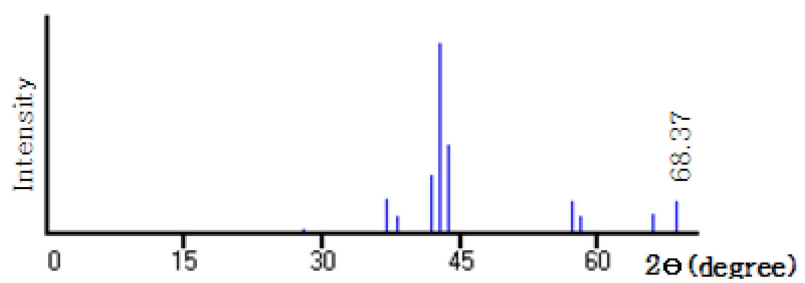

Fig. 3. X-ray diffraction peaks of carbide. ${ }^{10)}$

계 반응에 따라 고탄소 오스테나이트가 페라이트와 탄화물로 분해되어 생긴 탄화물의 피크로 예상된다. 하지만 그 강도가 $\mathrm{X}$-선 회절 패턴을 확대하여야 볼 수 있을 정도로 소량 존재한 다. Fig. 2의 (c)와 (d)에서 표시한 화살표 부분은 탄화물이 나타나는 위치이며, 이는 Fig. 3에서 확인할 수 있다[9].

\section{3 미세조직 분율 변화}

오스템퍼링 시간에 따른 미세조직을 구성하는 각 상의 양의 변화를 이미지 분석과 X-선 회절의 결과를 이용하여 관찰하였 다. 시편을 부식하여 미세조직을 관찰하였을 때 오스테나이트와 마르텐사이트 조직은 부식되지 않았고 페라이트 조직만이 부식 되었다. 이러한 사실을 바탕으로 페라이트 양을 이미지 분석으 로 측정하였다. 그리고 Table 3 은 X-선 회절의 결과 값으로
Table 3. Comparison between measured austenite volume fraction in XRD and image analysis of specimen austempered at $380^{\circ} \mathrm{C}$ with austempered time $32 \mathrm{~min}, 64 \mathrm{~min}$.

\begin{tabular}{cccc}
\hline \multicolumn{4}{c}{ Volume fraction of austenite } \\
\hline sample & XRD(Vol.\%) & Image analysis(Vol.\%) & Error(Vol.\%) \\
\hline 32 min & 24.81 & 24.80 & -0.01 \\
64 min & 24.33 & 24.12 & -0.21 \\
\hline
\end{tabular}

계산한 오스테나이트의 분율과 이미지 분석으로 측정한 오스테 나이트의 분율을 비교한 표이다. 32와 64 분에서는 다른 시간 조건에서와 달리 마르텐사이트 피크가 나타나지 않으므로 X-선 회절 피크를 이용하여 각각의 분율을 구할 수 있다.

32 와 64분에서 각각 측정된 오스테나이트 분율을 비교하였을 때 큰 오차가 없었으므로 이미지 분석 값을 적용할 수 있다고 판단하였다. 따라서 페라이트뿐만 아니라 오스테나이트와 마르 텐사이트의 분율을 구하기 위하여 이미지 분석을 이용하여 구 한 페라이트의 분율을 식 (1) (3)에 대입하여 오스테나이트와 마르텐사이트의 분율을 구하였다.

$$
\begin{aligned}
& \frac{I_{\gamma}}{I_{\alpha}}=\frac{R_{\gamma} V_{\gamma}}{R_{\alpha} V_{\alpha}} \\
& V_{\gamma}=\frac{I_{\gamma} R_{\alpha}}{I_{\alpha} R_{\gamma}} V_{\alpha} \\
& V_{\gamma}+V_{\alpha}+V_{M}=1
\end{aligned}
$$

$\mathrm{I}_{\alpha}$ 및 $\mathrm{I}_{\gamma}$ 는 오스테나이트와 페라이트의 적분강도 값이고, $\mathrm{R}_{\gamma}$ 및 $\mathrm{R}_{\alpha}$ 는 오스테나이트와 페라이트의 비례상수 값이며 $\mathrm{X}$-선 회 절 결과 값을 통하여 얻을 수 있다. $\mathrm{V}_{\gamma}, \mathrm{V}_{\alpha}$ 및 $\mathrm{V}_{\mathrm{M}}$ 는 각각 오스테나이트, 페라이트, 마르텐사이트의 분율로 $\mathrm{V}_{\alpha}$ 를 이미지 분석하여 구한 값을 대입하여 각각 구하였다. Table 4는 각각 의 미세조직의 분율을 계산한 값이다.

\subsection{Johnson-Mehl-Avrami식과의 비교}

Fig. 4는 3.3 절을 통하여 구한 페라이트와 오스테나이트 양 의 변화를 Johnson-Mehl-Avrami식과 비교한 것이다. JohnsonMehl-Avrami의 식 (4)는 핵생성과 성장에 대해 나타내는 식으 로 $\mathrm{n}$ 은 반응 지수(reaction exponent)이며 $\mathrm{k}$ 는 핵생성 및 성장 속도에 의해 결정되는 반응 상수(reaction constant)이다[10].

Table 4. Volume fraction of microstructures of specimen austempered at $380^{\circ} \mathrm{C}$ with austemping time.

\begin{tabular}{ccccccccccc}
\hline & Time (min) & 2 & 4 & 8 & 16 & 32 & 64 & 128 & 256 \\
\hline Micro-structure(Vol.\%) & & & & & & & & \\
\hline $\mathrm{V}_{\alpha}$ & 10.12 & 17.79 & 44.25 & 65.32 & 75.20 & 75.88 & 84.32 & 87.78 \\
$\mathrm{~V}_{\gamma}$ & 0.85 & 6.36 & 12.61 & 16.71 & 24.80 & 24.12 & 6.00 & 0 \\
$\mathrm{~V}_{\mathrm{M}}$ & 89.03 & 75.85 & 43.14 & 17.97 & 0 & 0 & 9.68 & 12.22 \\
Total & 100 & 100 & 100 & 100 & 100 & 100 & 100 & 100 \\
\hline
\end{tabular}




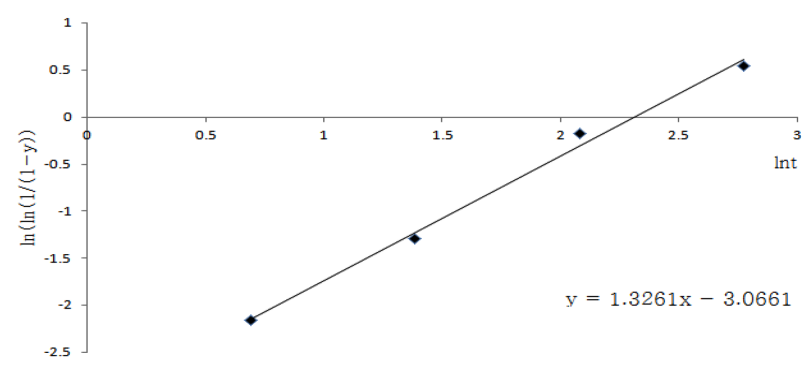

Fig. 4. Avrami plot about total volume fraction of ferrite and austenite after austempering at $380^{\circ} \mathrm{C}$ for $2,4,8,12$ and $32 \mathrm{~min}$.

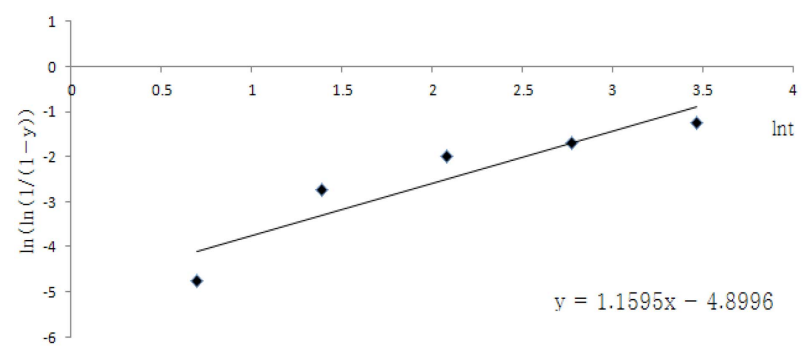

Fig. 5. Avrami plot about about volume fraction of austenite after austempering at $380^{\circ} \mathrm{C}$ for $2,4,8,12$ and $32 \mathrm{~min}$.

$$
\begin{aligned}
& y=1-\exp \left(-k t^{n}\right) \\
& \ln \left(\ln \left(\frac{1}{1-y}\right)\right)=n \ln t+\ln k
\end{aligned}
$$

$\mathrm{n}$ 과 $\mathrm{k}$ 의 값은 식 (5)를 이용하여 구하였다. $\mathrm{y}$ 값에는 각각의 시간에서 구한 분율을 대입하였고, t에는 해당하는 시간을 대입 하였다. 이때 그려지는 점들을 최소 자승법으로 직선을 그린 후 직선의 기울기를 $\mathrm{n}$ 값으로 하였고, $\mathrm{y}$ 절편 값을 $\ln k$ 값으로 하여 $\mathrm{k}$ 값을 구하였다. 아래 Fig. 4와 5는 식 (5)에 각각의 $\mathrm{y}$ 값과 t값을 대입하여 최소 자승법으로 직선화하였을 때의 그래 프와 그때의 직선에 대한 식을 나타낸 것이다. 이 때 구하여 지는 $\mathrm{n}$ 과 $\mathrm{k}$ 값은 Table 5 에 나타내었다. 그리고 이 $\mathrm{n}$ 과 $\mathrm{k}$ 값 을 식 (4)에 대입하여 구한 시간에 따른 분율 그래프를 이미 지분석과 직접 비교법으로 구한 변태 분율과 비교하여 Fig. 6 에 나타내었다.

1단계 반응이 일어나는 2 32분 동안 페라이트와 오스테나이 트의 분율 변화는 Johnson-Mehl-Avrami식과 거의 일치함을 보였다. 그러나 2단계 반응이 진행되는 $64 \sim 256$ 분에서는 Johnson-Mehl-Avrami식과 비교할 수 없었다. 페라이트의 경우 1 단계 반응의 고탄소 페라이트와 2단계 반응에서의 페라이트

Table 5. Calculated $\mathrm{n}$ and $\mathrm{k}$ values of Johnson-Mehl-Avrami equaion.

\begin{tabular}{ccc}
\hline & $\mathrm{n}$ & $\mathrm{k}$ \\
\hline $\begin{array}{c}\text { FERRITE+AUSTENITE } \\
\text { (Johnson-Mehl-Avrami) }\end{array}$ & 1.3230 & 0.0467 \\
AUSTENITE(Johnson-Mehl-Avrami) & 1.1527 & 0.0075 \\
\hline
\end{tabular}

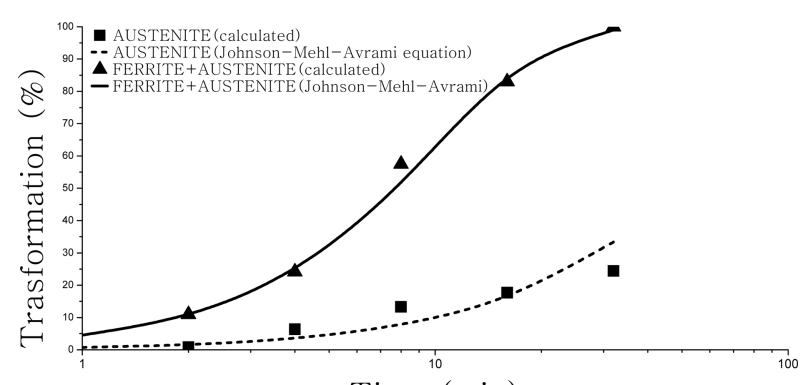

Time (min)

Fig. 6. Schematic representation of austempering reaction of specimen austempered at $380^{\circ} \mathrm{C}$ for $2 \sim 32 \mathrm{~min}$.

를 구분할 수 없었기 때문이었고, 오스테나이트의 경우는 감소 하는 상태로 Johnson-Mehl-Avrami을 만족하지 않기 때문이다.

\section{5 오스템퍼링 시간에 따른 페라이트와 오스테나이트의 양의 변화}

Fig. 7은 3.3절에서 구한 페라이트와 오스테나이트의 양의 변화를 오스템퍼링 시간에 따라 나타낸 것이다. 페라이트의 양 은 시간에 따라 점차 증가하며, 오스테나이트의 양은 32 64분 구간에서 최대 분율을 나타낸 후 64 분 이후 감소하였다. 이는 오스템퍼링 동안 일어나는 1단계와 2단계 반응을 살펴보면 그 이유를 알 수 있다. 2 32분의 구간은 1단계 반응을 진행하므 로 오스템퍼링 동안 미변태 오스테나이트기지가 고탄소 오스테 나이트와 고탄소 페라이트로 분해한다. 따라서 고탄소 오스테나 이트와 고탄소 페라이트가 생성되므로 두 조직 모두 계속하여 증가한다. 2단계 반응 동안에서는 고탄소 오스테나이트가 페라 이트와 탄화물로 분해하면서 1단계 반응과 비교하여 탄소의 양 이 적은 페라이트를 생성한다. 그러므로 페라이트는 1단계 반 응에 의해 생성된 고탄소 페라이트와 2단계 반응에 의해 생성 된 페라이트가 합쳐져 시간이 지남에 따라 점차 증가한다. 그 러나 오스테나이트는 1단계 반응에 의해 32 64분 구간 동안 생성되지만 64 분 이후 2 단계 반응의 시작으로 고탄소 오스테 나이트가 페라이트와 탄화물로 분해하며 점차 양이 감소한다. 이 때, 고탄소 오스테나이트는 갑자기 페라이트와 탄화물로 분 해되며 사라지는 것이 아닌 탄소양이 서서히 감소하면서 페라 이트와 탄화물로 분해한다. 이에 대한 것은 128 과 256 분에서

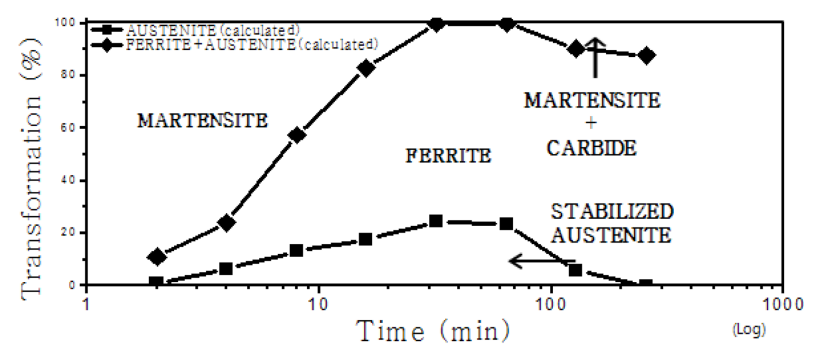

Fig. 7. Schematic representation of austempering reaction of specimen austempered at $380^{\circ} \mathrm{C}$ for $2 \sim 256 \mathrm{~min}$. 


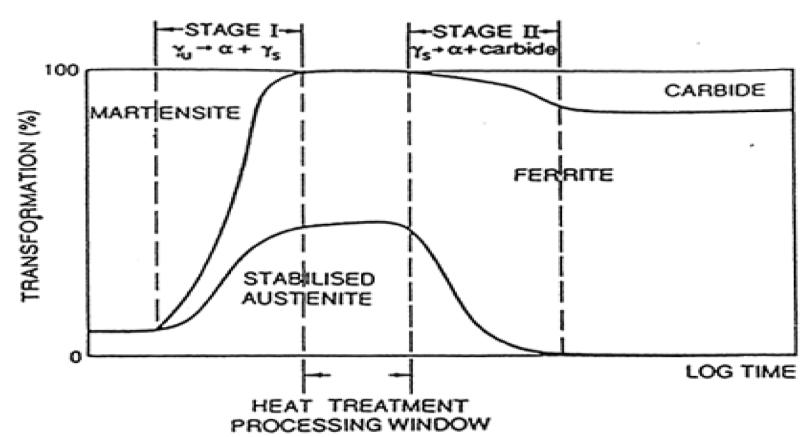

Fig. 8. Schematic representation of austempering reaction at high austempering temperature. ${ }^{8)}$

나타나는 마르텐사이트의 존재를 통해 확인할 수 있다. 만약 고탄소 오스테나이트가 순간적으로 페라이트와 탄화물로 분해해 사라져 버린다면 128 과 256분에서 오스테나이트 급랭으로 인 해 생성되는 마르텐사이트가 나타나지 않을 것이다. 마르텐사이 트는 $\mathrm{M}_{\mathrm{s}}$ 온도 이하로 냉각되면 $\mathrm{M}_{\mathrm{s}}$ 온도를 결정하는 탄소의 농 도에 해당하는 오스테나이트가 마르텐사이트로 변태하며 생성된 다. 128 과 256 분의 마르텐사이트는 물 퀜칭에 의한 $\mathrm{M}_{\mathrm{s}}$ 온도 이하에서의 냉각으로 조직 내 탄소의 양이 감소한 오스테나이 트 양만큼이 마르텐사이트로 변태를 하여 생성된 마르텐사이트 이다.

Fig. 8은 기존에 제안되었던 상부 오스템퍼링 반응의 모식도 이다. 본 실험을 통하여 그려진 Fig. 7과 비교하였을 때 반응 의 형태가 거의 유사함을 확인할 수 있었다. 또한, 이것을 통 하여 $\mathrm{Fe}-0.7 \mathrm{wt} . \% \mathrm{C}-2.3 \mathrm{wt} . \% \mathrm{Si}-0.3 \mathrm{wt} . \% \mathrm{Mn}$ 인 $\mathrm{ACSS}$ 의 $380^{\circ} \mathrm{C}$ 에 서의 오스템퍼링 반응이 고온에서의 오스템퍼링 반응을 만족하 고 있음을 확인할 수 있다.

\section{4. 결 론}

$\mathrm{Fe}-0.7 \mathrm{wt} . \% \mathrm{C}-2.3 \mathrm{wt} . \% \mathrm{Si}-0.3 \mathrm{wt} . \% \mathrm{Mn}$ 강을 동일하게 $900^{\circ} \mathrm{C}$ 에 서 60 분간 오스테나이타이징 처리하고 $380^{\circ} \mathrm{C}$ 에서 오스템퍼링 시간을 변화시키며 열처리를 한 결과, 오스템퍼링 변태 거동에 대하여 다음과 같은 결론을 얻었다.

1) 페라이트와 잔류 오스테나이트의 X-선 회절(XRD) 패턴 과 격자 상수 변화를 통하여 2 단계 반응 동안 잔류 오스테 나이트가 페라이트와 탄화물로 분해되었다.
2) 2 32분까지의 페라이트와 잔류 오스테나이트의 오스템퍼 링 시간에 따른 분율 변화는 Johnson-Mehl-Avrami식으로 계 산한 값과 대부분 일치하였다.

3) 오스템퍼링 시간이 증가함에 따라 페라이트 양은 1 단계 와 2 단계 반응의 영향으로 점차 증가하며, 잔류 오스테나이트 양은 반응 1 단계 동안은 증가하고 반응 2 단계 이후부터는 감소하였다.

4) $\mathrm{Fe}-0.7 \mathrm{wt} . \% \mathrm{C}-2.3 \mathrm{wt} . \% \mathrm{Si}-0.3 \mathrm{wt} . \% \mathrm{Mn}$ 강의 $380^{\circ} \mathrm{C}$ 에서의 오스템퍼링 시간에 따른 반응은 상부 오스템퍼링 반응을 만족 하였다.

\section{감사의 글}

이 논문은 2012학년도 경북대학교 학술연구비에 의하여 연 구되었음

\section{References}

[1] A. Nazarboland and R. Elliott, "Materials Science and Technology", 13 (1997) 223.

[2] D. C. Wen and T. S Lei, "Material Transaction", 40 (1999) 980.

[3] N. Darwish and R. Elliot, "Materials Science and Technology", 9 (1993) 586.

[4] G. L. Greno, J. L. Otegui, R. E. Boeri, "International Journal of Fatique", 21 (1999) 35.

[5] Yanxiang Li, Xiang Chen, "Materials Science and Engineering", A308 (2001) 277.

[6] J. Shi, S. Zor, J. J. M. Too and R. W. Smith, "Cast Metals", 5 (1992) 103.

[7] R. C. Voigt, “AFS Transactions”, 173 (1989) 915.

[8] J. Y. Son, J. H. Kim, W. B. Kim, B. Y. Ye, "Met, Mater. Int", 16 (2010) 357-361.

[9] ICDD: Powder Diffraction File Sets 1-45, Neston Square Corporated Campus, Pennsylvania, (1995).

[10] S. H. Lee, "The Effects of Si and Austenite Grain Size on the Ferrite Transformation by Using the Classical Nucleation \& Growth Theory", Hanyanng university, (2008). 